\title{
Quantificação da erosão em pastagem com diferentes declives na microbacia do Ribeirão Salomea ${ }^{1}$
}

\author{
Euzelina dos S. B. Inácio ${ }^{2}$, José R. B. Cantalice ${ }^{3}$, Paulo G. S. Nacif ${ }^{4}$, Quintino R. de Araujo ${ }^{5}$ \& Arlete C. Barreto $^{6}$
}

\begin{abstract}
RESUMO
A erosão hídrica é uma das principais formas de degradação do solo e, dentre os diversos fatores que exercem influência sobre ela, dois se destacam: a cobertura do solo e a declividade do terreno. Com este trabalho, objetivou-se quantificar as perdas de solo por erosão hídrica sob chuva simulada em cobertura de pastagem comparando-as com solo descoberto em diferentes classes de declividade e avaliar a erodibilidade do solo estudado, visando avaliar a capacidade dessa cobertura vegetal em proteger o solo da erosão, bem como a influência da declividade da área nas perdas de solo, para as condições da microbacia do Ribeirão Salomea, sul da Bahia. Os tratamentos com quatro repetições foram: com e sem cobertura de pastagem em quatro classes de declive: < 9, 10-15, 25-30 e 35-40\%. Aplicaram-se 32 chuvas simuladas em parcelas delimitadas por chapas metálicas cravadas no solo, com uma calha coletora para a amostragem da enxurrada. Os resultados mostraram que a cobertura do solo influenciou as perdas, dentro de cada classe de declive. Ocorreu aumento das perdas com o aumento de declividade do terreno, as quais foram maiores no tratamento sem cobertura que naquele com cobertura. Para o Chernossolo Argilúvico órtico típico estudado, o valor da erodibilidade foi de $1,48 \times 10^{5} \mathrm{~kg} \mathrm{~s} \mathrm{~m}^{-4}$.
\end{abstract}

Palavras-chave: erosão hídrica, chuva simulada, perda de solo

\section{Erosion quantification in pastures with different slopes in the Ribeirão Salomea Watershed}

\begin{abstract}
The water erosion is one of the main forms of soil degradation and it is highly affected by the soil cover and landscape slope. The objective of this work was to quantify the detachment rate and the soil loss due to water erosion under simulated rains in pastures, as well as to study the effect of land cover and the slope classes $(<9,10-15,25-30$ and 35-40\%) on soil loss in the Ribeirão Salomea wathershed. The treatments with four repetitions were: with and without pasture covering in four slope classes: $<9,10-15,25-30$ and 35-40\%. Thirty-two simulated rains were applied in plots delimited by galvanized metallic foils fixed in the soil and having a gutter at their lower part for runoff sampling. The results showed that the land cover influenced soil loss only within each slope classes. Soil losses increased with increasing slope classes. This phenomenon was higher in uncovered land than in the covered ones. The erodibility was $1.48 \times 10^{5} \mathrm{~kg} \mathrm{~s} \mathrm{~m}^{-4}$ for the evaluated Mollisol.
\end{abstract}

Key words: water erosion, simulated rains, soil loss

\footnotetext{
1 Parte da Dissertação de Mestrado do primeiro autor

2 Doutoranda em Ciências do Solo, UFLA. CEP 37200-000, Lavras. Fone: (35) 3829-1252. E-mail: euzi inacio@yahoo.com.br

3 Departamento de Agronomia/UFRPE. CEP 52171-900, Recife, PE. E-mail: cantalic@terra.com.br.

${ }^{4}$ Escola de Agronomia/UFBA, CEP 44380-000, Cruz das Almas, BA. E-mail: pgabriel@ufba.br

${ }^{5}$ UESC. Pesquisador do Centro de Pesquisas do Cacau da CEPLAC. CEP 45690-000, Ilhéus, BA. E-mail: quintino@cepec.gov.br

${ }^{6}$ UFRPE. Rua Dom Manoel de Medeiros, s/n. CEP 52171-900, Recife, PE. E-mail: arletecortes@yahoo.com.br
} 


\section{INTRODUÇÃO}

A região sul da Bahia abriga uma grande área de remanescente da Mata Atlântica no País, razão porque possui enorme responsabilidade no processo de conservação desta. A cultura cacaueira contribuiu muito para essa conservação visto que o cacau é cultivado sob a Mata Atlântica raleada, ou seja, neste sistema as árvores são preservadas e apenas o primeiro substrato da vegetação é retirado para a implantação da cultura. Entretanto, de acordo com Costa et al. (1999) diversos fatores de ordem econômica, política e climática, causaram a retirada de cacauais e expansão de pastagens inicialmente formadas de Colonião (Panicum maximum Jacq.) e sempre-verde (Panicum maximum Jacq. var. gangyloides Doell). Este fato provocou uma modificação da cobertura vegetal original de grande parte desse ecossistema, chamando a atenção para a sustentabilidade do sistema regional.

Este manejo inadequado do solo e a erosão hídrica são apontados por Martins et al. (2003) como os principais causadores da constante redução da produtividade dos solos os quais destacam, ainda, outro aspecto de grande relevância, ou seja, o fato de que o aporte de sedimentos oriundos de áreas que sofrem erosão, promove o assoreamento de rios e lagos, comprometendo a qualidade da água e alterando a vida aquática, principalmente pela eutrofização das águas.

A erosão hídrica do solo é um processo físico de desagregação, transporte e deposição de partículas do solo, provocado pela ação da água das chuvas e do escoamento superficial e afetada pela ação antrópica (Cassol \& Lima, 2003). A desagregação é provocada, sobretudo pelo impacto das gotas da chuva diretamente sobre a superfície do solo, causando ruptura dos agregados. O transporte das partículas finas desagregadas dá-se quando o solo está saturado ou quando a velocidade de água precipitada é superior a capacidade de infiltração de água no solo, ocasionando o escoamento superficial do excesso de água, em áreas com declive. Finalmente, o material transportado se deposita em locais mais baixos, que podem ser depressões naturais do terreno ou reservatório de água, como rios, lagos, açudes, represas, concluindo o processo erosivo (Eltz et al.,1984).

A magnitude das perdas por erosão depende de uma série de fatores, dentre os quais destacam-se a cobertura vegetal (Silva, 1986) e a declividade da área (Watson \& Laflen, 1986; Amorim et al., 2001; Cogo et al., 2003).

Compreender os fatores que integram o processo de erosão do solo e quantificar as perdas de solo é de grande importância, pois serve como base na elaboração de medidas que visem maximizar o uso dos recursos hídricos disponíveis e evitar os efeitos negativos decorrentes da produção, transporte e deposição de sedimentos (Paiva, 2001).

O objetivou-se com este trabalho quantificar as perdas de solo por erosão hídrica sob chuva simulada em cobertura de pastagem comparando-as com solo descoberto em diferentes classes de declividade e avaliar a erodibilidade do solo estudado para as condições da microbacia hidrográfica do Ribeirão Salomea, visando avaliar a capacidade dessa cobertura vegetal em proteger o solo da erosão e a influência da declividade da área nas perdas de solo.

\section{MATERIAL E MÉTODOS}

O estudo foi desenvolvido em área da microbacia hidrográfica do Ribeirão Salomea, compreendida entre as coordenadas $14^{\circ} 45^{\prime} / 14^{\circ} 55^{\prime} \mathrm{S}$ e $39^{\circ} 35^{\prime} / 39^{\circ} 45^{\prime} \mathrm{W}$ e representando uma área de 5.820 ha, na região sul da Bahia, em área da Bacia Hidrográfica do Rio Cachoeira (BHRC). O clima da área corresponde ao tipo Am, tropical quente e úmido, com estação seca compensada pelos totais elevados, conforme classificação de Köepen (Araújo et al., 2002). No momento deste estudo, a área era utilizada em sistema de pastagem com capim colonião (Panicum maximum).

O solo predominante na área foi classificado como Chernossolo Argilúvico Órtico típico (Nacif, 2000). As amostras coletadas na área estudada foram submetidas à caracterização física e química (Tabela 1).

Tabela 1. Caracterização química e física do solo $(0-20 \mathrm{~cm})$ utilizado no experimento

\begin{tabular}{|c|c|c|c|c|}
\hline \multirow{2}{*}{ Característica } & \multicolumn{4}{|c|}{ Classes de declives (\%) } \\
\hline & $<9$ & $10-15$ & $20-30$ & $35-40$ \\
\hline pH em água ${ }^{1}$ & 5,8 & 7,0 & 5,2 & 6,3 \\
\hline $\mathrm{Ca}\left(\mathrm{cmolc} \mathrm{dm}^{-3}\right)^{1}$ & 3,2 & 4,0 & 2,2 & 8,0 \\
\hline $\mathrm{Ca}+\mathrm{Mg}\left(\mathrm{cmol}_{\mathrm{c}} \mathrm{dm}^{-3}\right)^{1}$ & 10,0 & 9,0 & 4,0 & 10,0 \\
\hline $\mathrm{Al}\left(\mathrm{cmol}_{\mathrm{c}} \mathrm{dm}^{-3}\right)^{1}$ & 0,05 & 0,05 & 0,15 & 0,05 \\
\hline $\mathrm{Na}\left(\mathrm{cmol}_{\mathrm{c}} \mathrm{dm}^{-3}\right)^{1}$ & 0,109 & 0,135 & 0,039 & 0,043 \\
\hline$P\left(m g d m^{-3}\right)^{1}$ & 5,92 & 5,23 & 13,14 & 6,63 \\
\hline $\mathrm{K}\left(\mathrm{cmol}_{\mathrm{c}} \mathrm{dm}^{-3}\right)^{1}$ & 0,01 & 0,01 & 0,03 & 0,01 \\
\hline Areia $(\%)^{1}$ & 72 & 69 & 66 & 59 \\
\hline Silte $(\%)^{1}$ & 10 & 20 & 25 & 30 \\
\hline Argila $(\%)^{1}$ & 18 & 11 & 9 & 11 \\
\hline Densidade do solo $\left(\mathrm{g} \mathrm{cm}^{-3}\right)^{2}$ & 1,39 & 1,34 & 1,25 & 1,29 \\
\hline Densidade de partículas $\left(\mathrm{g} \mathrm{cm}^{-3}\right)^{3}$ & 2,68 & 2,82 & 2,78 & 2,73 \\
\hline Condutividade hidráulica $\left(\mathrm{cm} \mathrm{h}^{-1}\right)^{4}$ & 50 & 45 & 78 & 23 \\
\hline Capacidade de campo $(\%)^{1}$ & 2,46 & 2,66 & 2,83 & 3,81 \\
\hline Ponto de murcha permanente $(\%)^{1}$ & 1,25 & 1,48 & 1,65 & 2,17 \\
\hline
\end{tabular}

${ }^{1}$ EMBRAPA (1997); ${ }^{2}$ Método da proveta; ${ }^{3}$ Método do balão volumétrico; ${ }^{4}$ Método do funil com amostras indeformadas

Os tratamentos corresponderam a quatro declives e duas condições de cobertura do solo: com e sem cobertura de pastagem de capim colonião (Panicum maximum), totalizando oito tratamentos e trinta e duas unidades experimentais. Os tratamentos foram: sem cobertura e declive $<9 \%$; com cobertura e declive < $9 \%$; sem cobertura e declive $10-15 \%$; com cobertura e declive 10-15\%; sem cobertura e declive 25-30\%; com cobertura e declive 25-30\%; sem cobertura e declive $35-40 \%$ e com cobertura e declive 35-40\%.

As parcelas foram delimitadas por chapas metálicas galvanizadas cravadas no solo, e possuíam, na parte inferior, uma calha coletora para amostragem da enxurrada. As dimensões da parcela foram de $1 \mathrm{~m}$ de largura e $3 \mathrm{~m}$ de comprimento, situando-se a maior dimensão no sentido do declive.

As chuvas simuladas foram aplicadas durante o mês de maio de 2004, utilizando-se um simulador de chuva desenvolvido no Laboratório de Conservação do Solo do Departamento de Agronomia da UFRPE, que se constitui de um bico aspersor tipo Veejet 80-150 com diâmetro interno de 
1/2 polegada, instalado a uma altura de 3,10 m da superfície do solo e com pressão de saída de $41 \mathrm{kPa}$. O simulador foi abastecido através de uma bomba “Diafragma”, disponibilizando água de um reservatório para formação das chuvas, que tiveram duração de 40 min, e intensidade média de $97,05 \mathrm{~mm} \mathrm{~h}^{-1}$ monitorada através de um conjunto de 10 pluviômetros colocados ao lado da área útil das parcelas experimentais.

Coletaram-se, durante o escoamento, amostras de enxurrada de 5 em 5 min, utilizando-se uma proveta graduada, durante $5 \mathrm{~s}$ para em seguida serem armazenadas em potes plásticos com capacidade de $1 \mathrm{~L}$.

Para determinação das porcentagens de cobertura do solo, utilizou-se o método de Mannering, descrito por Bezerra et al. (2002), que utiliza a projeção fotográfica de uma moldura com a cobertura vegetal da área; para isto, fotografou-se em campo uma moldura de 76 x $51 \mathrm{~cm}$ sobre uma área representativa da parcela, para posterior sobreposição da imagem em um quadro padrão, fazendo-se a soma das interseções, com os pontos de cobertura vegetal da superfície obtendo-se, desta forma, a porcentagem total de cobertura vegetal.

As amostras de enxurrada coletadas no campo foram levadas ao laboratório e pesadas para determinação do teor de solo e água. Adicionaram-se $5 \mathrm{~mL}$ de sulfato de alumínio dodecahidratado para deposição das partículas; 24 h depois, o sobrenadante foi succionado e os potes levados para secagem em estufa a $65^{\circ} \mathrm{C}$ e logo após pesados com o solo seco.

As taxas de desagregação em entressulcos $\left(\mathrm{kg} \mathrm{m}^{-2} \mathrm{~s}^{-1}\right)$ e perdas de solo foram determinadas segundo as equações:

$$
\begin{aligned}
\mathrm{D} & =\text { Mss } / \text { A.Dc } \\
\text { PS } & =\Sigma(\text { Q.Cs.t }) / A
\end{aligned}
$$

em que:

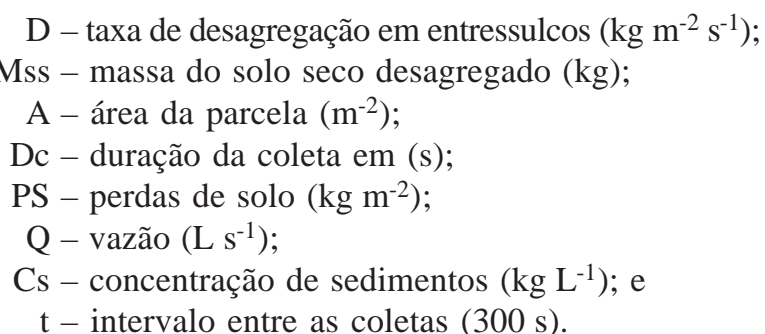

A erodibilidade em entressulcos do solo (Ki) foi calculada de acordo com a equação

$$
\mathrm{Di}=\mathrm{Ki} \mathrm{i}^{2} \mathrm{~S}_{\mathrm{f}}
$$

em que: Di - taxa de desagregação em entressulcos $\left(\mathrm{kg} \mathrm{m}^{-2} \mathrm{~s}^{-1}\right)$; $\mathrm{i}$ - intensidade da chuva $\left(\mathrm{m} \mathrm{s}^{-1}\right)$; o fator declividade: $\mathrm{S}_{\mathrm{f}}=1,05-$ 0,85 exp(-4 sen q), em que: q ângulo do declive. Observaramse as taxas máximas de desagregação do solo nos últimos 30 minutos de chuva, de acordo com Elliot et al. (1989) para o solo descoberto.

O delineamento experimental foi o inteiramente casualizado, em esquema fatorial 4 x 2 (quatro declives e duas condições de cobertura), com quatro repetições. Os resultados foram submetidos a análise de regressão, variância e com- paração de médias através do teste $\mathrm{F}$, a 5\%. Utilizou-se o programa estatístico SAS - Statistical Analitical System (SAS Institute, 1998).

\section{RESULTADOS E DISCUSSÃO}

Verifica-se através do comportamento do escoamento superficial verifica-se que para o solo descoberto o tempo de início do escoamento ocorreu entre 0,7 e 1,8 min (Figura 1), por outro lado, foi maior para o solo com cobertura vegetal, variando entre 2,4 e 4,8 min, resultado semelhante ao encontrado por Mello et al. (2003).

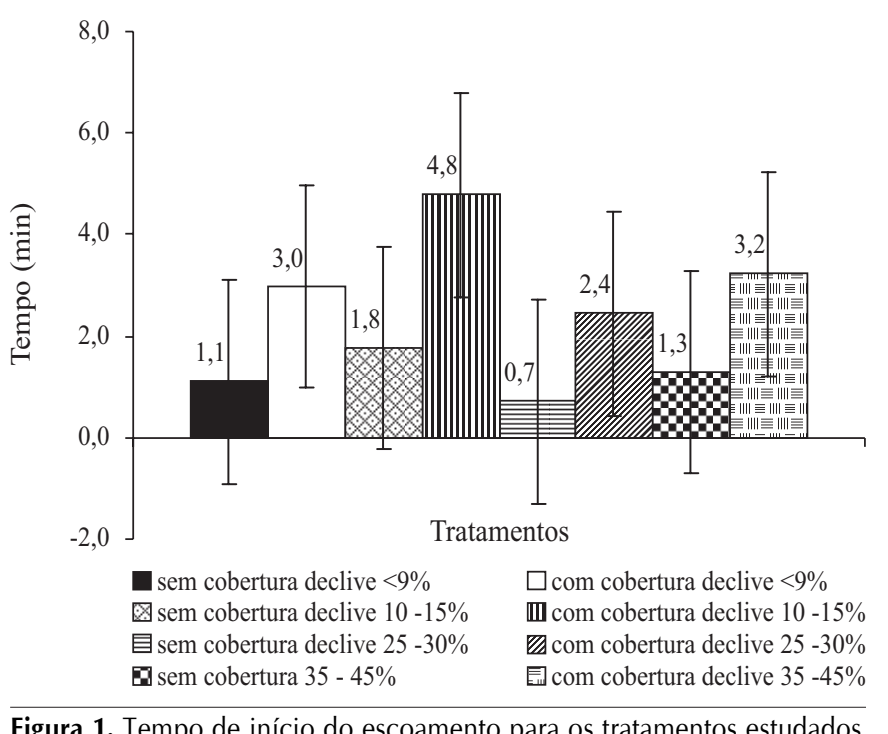

Figura 1. Tempo de início do escoamento para os tratamentos estudados

De acordo com Bertol et al. (1997) a superfície do solo descoberta fica exposta ao impacto direto das gotas de chuva, promovendo o selamento superficial, reduzindo a taxa de infiltração de água e, conseqüentemente, ocorre o início do escoamento superficial. Esse fato, justifica o maior tempo de início do escoamento no tratamento com cobertura, indicando a proteção contra o impacto da gota de chuva que a cobertura vegetal estudada promove. Entretanto, os efeitos da declividade nesse processo não foram suficientemente claros.

De modo geral, as taxas de desagregação (Figura 2), foram maiores no solo descoberto relativamente ao solo com cobertura, independentemente do declive. Este resultado indica o efeito da proteção promovido pela cobertura vegetal, que reduziu a desagregação de partículas do solo, provavelmente por diminuir a área exposta ao impacto direto das gotas de chuva. Diversos autores (Schäffer et al., 2001; Cantalice, 2002; Bezerra, 2003; Cassol et al., 2004), também perceberam redução nas taxas de desagregação com a utilização de cobertura vegetal.

Mannering \& Meyer (1963) explicam que os resíduos vegetais na superfície do solo interceptam as gotas de chuva e dissipam a sua energia, evitando a desagregação das partículas e a formação do selo superficial. Além disso, há redução na velocidade da enxurrada e conseqüentemente 


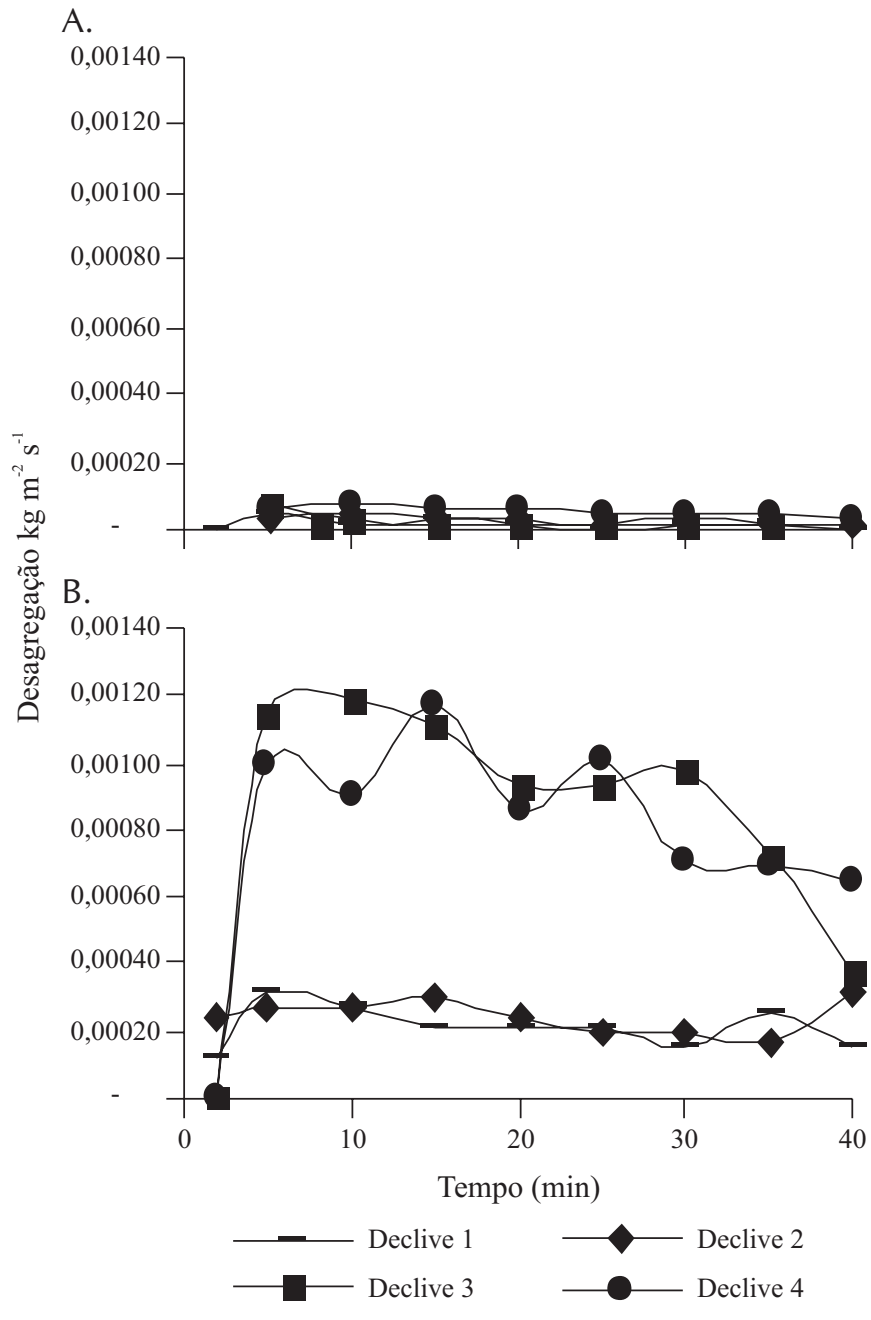

Figura 2. Evolução da taxa de desagregação do solo (A) com cobertura vegetal (B) solo descoberto, de acordo com a classe de declividade do terreno

redução na sua capacidade de desagregação e transporte de partículas do solo.

O efeito do declive foi mais pronunciado para o solo descoberto, verificando-se que as maiores taxas de desagregação foram observadas para os maiores declives (25-30\% e $35-45 \%$ ) sendo importante destacar que no inicio da chuva ocorreu um aumento da desagregação, a qual decresceu ao longo do tempo.

Este crescimento inicial das taxas de desagregação do solo está relacionado ao das taxas de descarga líquida que, no início da chuva, é muito pequeno devido a infiltração ser mais elevada e, assim, o fluxo superficial é relativamente pequeno, não tendo capacidade para transportar todo o material desagregado pela ação do impacto das gotas de chuva. A medida em que o fluxo cresce, com o transcorrer do tempo de chuva se torna capaz de transportar todo o material desagregado instantaneamente, ou seja, aquele remanescente do período inicial, quando havia limitação da capacidade de transporte (Braida \& Cassol, 1999).

Para a concentração de sedimentos (Tabela 2) o comportamento foi semelhante ao das outras variáveis analisadas, verificando-se os maiores valores na condição sem cobertu- ra do solo, enquanto os valores com cobertura de pastagem foram significativamente menores. Esses resultados corroboram com os encontrados por Braida \& Cassol (1999) e Schäffer et al. (2001).

As perdas de solo para os declives 10-15, 25-30, 35-40\%, na condição sem cobertura foram significativamente maiores que no solo com cobertura de gramínea. No declive 10-15\% encontraram-se valores de $6,5 \mathrm{t} \mathrm{ha}^{-1}$ no tratamento sem cobertura, enquanto para a condição com cobertura as perdas foram de 0,58 $\mathrm{t} \mathrm{ha}^{-1}$, ou seja, 11 vezes menores. Enquanto isso, nos maiores declives, $25-30$ e $35-40 \%$, as perdas foram de 26,85 e 20,83 tha-1 sem cobertura e 0,64 e 1,23 tha-1 com cobertura respectivamente. Quando sob cobertura de gramínea, esses baixos valores de erosão podem, ser atribuídos principalmente à interceptação das gotas de chuva e á barreira física promovida pelas gramíneas da pastagem.

Tabela 2. Efeito da cobertura vegetal entre as classes de declives sobre a concentração de sedimentos, desagregação, vazão e perdas de solo

\begin{tabular}{|c|c|c|c|c|}
\hline $\begin{array}{l}\text { Declive } \\
(\%)\end{array}$ & $\begin{array}{l}\text { Concentração } \\
\text { de sedimentos } \\
\left(\mathrm{kg} \mathrm{L}^{-1}\right)\end{array}$ & $\begin{array}{c}\text { Desagregação } \\
\left(\mathrm{kg} \mathrm{m}^{-2} \mathrm{~s}^{-1}\right)\end{array}$ & $\begin{array}{l}\text { Vazão } \\
\left(L^{-1}\right)\end{array}$ & $\begin{array}{l}\text { Perdas de } \\
\text { solo } \\
\left(\mathrm{t} \mathrm{ha}^{-1}\right)\end{array}$ \\
\hline \multicolumn{5}{|c|}{ Sem cobertura } \\
\hline$>9$ & $2,84 \times 10^{-3} \mathrm{~A}$ & $1,20 \times 10^{-4} \mathrm{~A}$ & $0,13 \mathrm{~A}$ & $3,70 \mathrm{~A}$ \\
\hline $10-15$ & $5,29 \times 10^{-3} \mathrm{~A}$ & $2,28 \times 10^{-4} \mathrm{~A}$ & $0,13 \mathrm{~A}$ & $6,50 \mathrm{~A}$ \\
\hline $25-30$ & $2,21 \times 10^{-2} \mathrm{~A}$ & $8,57 \times 10^{-4} \mathrm{~A}$ & $0,11 \mathrm{~A}$ & $26,86 \mathrm{~A}$ \\
\hline $35-40$ & $2,14 \times 10^{-2} \mathrm{~A}$ & $7,88 \times 10^{-4} \mathrm{~A}$ & $0,11 \mathrm{~A}$ & $20,83 \mathrm{~A}$ \\
\hline \multicolumn{5}{|c|}{ Com cobertura } \\
\hline$>9$ & $3,35 \times 10^{-4} \mathrm{~A}$ & $1,10 \times 10^{-5} \mathrm{~A}$ & $0,10 \mathrm{~A}$ & $0,48 \mathrm{~A}$ \\
\hline $10-15$ & $6,43 \times 10^{-4} \mathrm{~B}$ & $1,93 \times 10^{-5} \mathrm{~B}$ & $0,07 \mathrm{~A}$ & $0,58 \mathrm{~B}$ \\
\hline $25-30$ & $5,65 \times 10^{-4} \mathrm{~B}$ & $1,75 \times 10^{-5} \mathrm{~B}$ & $0,15 \mathrm{~A}$ & $0,64 \mathrm{~B}$ \\
\hline $35-40$ & $1,47 \times 10^{-3} \mathrm{~B}$ & $4,5 \times 10^{-5} \mathrm{~B}$ & $0,09 \mathrm{~A}$ & $1,23 \mathrm{~B}$ \\
\hline
\end{tabular}

Médias de 4 repetições. Médias seguidas de mesma letra na coluna dentro de cada classe de declive não diferem de acordo com o teste de Tukey

Ainda em relação à Tabela 2, percebe-se que as vazões obtidas para os diferentes tratamentos não foram significativas, muito embora as perdas de solo tenham sido significativamente diferentes. Tal fato atesta a ocorrência da erosão em entressulcos que se caracteriza pela desagregação do solo devido ao impacto das gotas de chuva demonstrando que a lâmina de escoamento pouco espessa na erosão em entressulcos mais transporta o sedimento desagregado pela chuva, pouco desagregando solo por conta de sua pouca quantidade de energia, o que está de acordo com Govers (1996).

Analisando-se as perdas de solo em função da declividade (Figura 3), nota-se que estas só foram significativas quando o solo se encontrava descoberto, o que ressalta a importância promovida pela cobertura vegetal de pastagem, que atuou interceptando as gotas de chuva reduzindo em conseqüência a concentração de sedimentos, que contribuem para as perdas de solo.

De modo geral, os valores mais altos de perda de solo ocorreram entre as classes $25-30$ e $35-40 \%$ e os mais baixos entre as classes $<9 \%$ e $10-15 \%$, mostrando que há aumento das perdas de solo com o aumento da declividade. Estes resultados também foram confirmados por diversos autores (Meyer et al., 1983; Watson \& Laflen, 1986; Pereira et al., 2003). 
Tal comportamento das perdas em relação à declividade pode ser justificado pelo aumento da capacidade erosiva da enxurrada nos declives mais acentuados, decorrentes do aumento da sua velocidade, conforme também foi sugerido por Cogo et al. (2003).

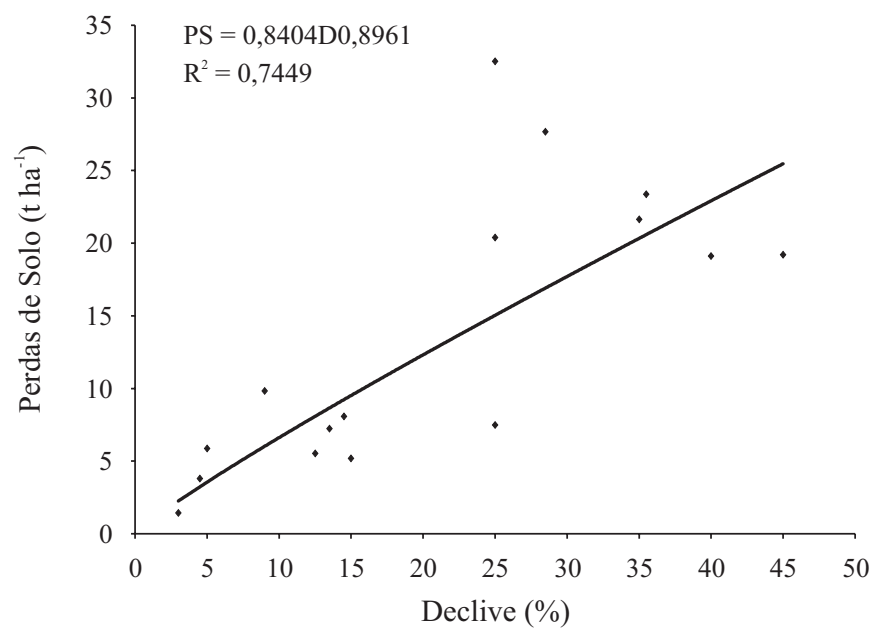

Figura 3. Perdas de solo em função do declive

Os percentuais de cobertura vegetal determinados em campo foram de $100 \%$ de cobertura para todas as parcelas demonstrando, assim, uniformidade entre os testes realizados nas parcelas com cobertura de pastagem.

$\mathrm{O}$ valor de erodibilidade em entressulcos (Ki), para o horizonte A do Chernossolo Argilúvico determinado em campo, para as parcelas descobertas, foi de $1,48 \times 10^{5} \mathrm{~kg} \mathrm{~s} \mathrm{~m}^{-4}$. Este valor de erodibilidade é inicial e de referência para o solo estudado; no entanto, é menor, se comparado com valores também obtidos para o horizonte A, de um Argissolo Vermelho distrófico típico, por Cantalice (2002) e Braida \& Cassol (1999), respectivamente de Ki de 2,55 x $10^{6} \mathrm{~kg} \mathrm{~s} \mathrm{~m}^{-4}$ e $5,1 \times 10^{6} \mathrm{~kg} \mathrm{~s} \mathrm{~m}^{-4}$, o que pode ser justificado em virtude dos Chernossolos apresentarem colóides orgânicos e inorgânicos predominantemente em estado de floculação, segundo EMBRAPA (1999). Ressalta-se, que os Argissolos também ocorrem na microbacia do Ribeirão Salomea.

\section{CONCLUSÕES}

1. A cobertura do solo por pastagem foi eficiente quanto a proteger o solo da erosão em relação ao solo sem cobertura.

2. Ocorreu aumento das perdas com o aumento dos valores das classes de declividade do terreno, as quais foram maiores no tratamento sem cobertura que no com cobertura.

3. Para o Chernossolo Argilúvico órtico típico estudado, o valor da erodibilidade foi de $1,48 \times 10^{5} \mathrm{~kg} \mathrm{~s} \mathrm{~m}^{-4}$.

\section{AGRADECIMENTOS}

Os autores agradecem ao Conselho Nacional de Desenvolvimento Científico e Tecnológico pela concessão de bol- sa de mestrado ao primeiro autor; ao Centro de Pesquisa da Lavoura Cacaueira (CEPLAC) e á Universidade Federal da Bahia (UFBA), pelo total apoio nos trabalhos de campo.

\section{LITERATURA CITADA}

Amorim, R. S. S.; Silva, D. D.; Pruski, F. F.; Matos, A. T. de. Influência da declividade do solo e da energia cinética de chuvas simuladas no processo de erosão entre sulcos. Revista Brasileira de Engenharia Agrícola e Ambiental, Campina Grande, v.5, n.1, p.124-130, 2001.

Araújo, Q. R.; Araújo, M. H. S.; Sampaio, J. O. Análise do risco de erosão em microbacias hidrográficas: estudo de caso das bacias hidrográficas dos rios Salomé e Areia, sul da Bahia. In: Schiavetti, A.; Camargo, A. F. M. (Org.) Conceito de bacias hidrográficas: Teorias e aplicações. Ilhéus: EDITUS, 2002. p.163-177.

Bertol, I.; Cogo, N. P.; Levien, R. Erosão hídrica em diferentes preparos do solo logo após as colheitas de milho e trigo, na presença e ausência de resíduos culturais. Revista Brasileira de Ciência do Solo, Campinas, v.21, n.3, p.409-418, 1997.

Bezerra, S. A. Avaliação da erosão em entressulcos na cultura da cana de açúcar. Recife: UFRPE, 2003. 64p. Dissertação Mestrado

Bezerra, S. A.; Cantalice, J. R. B.; Tarquir, J. L. Z. Características do escoamento superficial e taxas de erosão em uma área sob cultivo agrícola. In: Encontro Nacional de Engenharia de Sedimentos, 5, 2002, São Paulo. Anais... São Paulo: ABRH, 2002. p.403.

Braida, J. A.; Cassol, E. A. Relações da erosão em entressulcos com o tipo e com a quantidade de resíduo vegetal na superfície do solo. Revista Brasileira de Ciência do Solo, Viçosa, v.23, p.711-721, 1999.

Cantalice, J. R. B. Escoamento e erosão em sulcos e entressulcos em distintas condições de superfície do solo. Porto Alegre: UFRGS, 2002. 141p. Tese Doutorado

Cassol, E. A.; Cantalice, J. R. B.; Reicherdt, J. M.; Mondardo, A. Escoamento superficial e desagregação do solo em entressulcos em solo franco-argilo-arenoso com resíduos vegetais. Pesquisa Agropecuária Brasileira, Brasília, v.39. n.7, p.685-690, 2004.

Cassol, E. A.; Lima, V. S. Erosão em entressulcos sob diferentes tipos de preparo e manejo do solo. Pesquisa Agropecuária Brasileira, Brasília, v.38, n.1, p.117-124, 2003.

Cogo, N. P.; Levien R.; Schwarz, R. A. Perdas de solo e água por erosão hídrica influenciadas por métodos de preparo, classes de declive e níveis de fertilidade do solo. Revista Brasileira de Ciência do Solo, Viçosa, v.27, n.4, p.743-753, 2003.

Costa, O. V.; Fontes, L. E. F.; Costa, L. M. da; Ker, J. C. ; Araújo, Q. R.; Nacif, P. G. S. Histórico de Uso e ocupação das regiões pastoris dos municípios de Itapé e Itajú do Colônia Bahia. In: Reunião Brasileira de Manejo e Conservação do Solo e da Água, 18, 1999, Ilhéus. Anais... Ilhéus: CEPLAC, 1999. CD Rom.

Elliot, W. J.; Liebnow, A. M.; Laflen, J. M.; Kohl, K. D. A compendium of soil erodibility data from WEPP cropland soil field erodibility experiments 1987 e 88 . West Lafayette: The Ohio State University, 1989, p.A2-A25, (NSERL - National Soil Erosion Research Laboratory Report, 3). 
Eltz, F. L. F.; Cassol, E. A. ; Scopel, I. Guerra, M. Perdas de solo e água por erosão em diferentes sistemas de manejo e coberturas vegetais em solo laterítico Bruno - avermelhado distrófico (São Jerônimo) sob chuva natural. Revista Brasileira de Ciência do Solo, Campinas, v.8, n.1, p.117125, 1984.

EMBRAPA - Empresa Brasileira de Pesquisa Agropecuária. Centro Nacional de Pesquisa de Solos. Manual de métodos de análise de solos. 2.ed. Rio de Janeiro: EMBRAPA, 1997. 212p.

EMBRAPA - Empresa Brasileira de Pesquisa Agropecuária. Centro Nacional de Pesquisa de Solos. Sistema brasileiro de classificação de solos. Brasília: EMBRAPA, 1999. 412p.

Govers, G. Soil erosion process research: A state of the art. Brussel: Paleis der Academien, 1996. 53p. Klasse der Wetenschappen, Jaargang 58, n.1

Mannering, J. V.; Meyer, L. D. The effects of various rats of surface mulch on infiltration and erosion. Soil Science Society of American Proceeding, Madison, v.27, n.1, p.84-86, 1963.

Martins, S. G.; Silva, M. L. N.; Curi, N.; Ferreira, M. M.; Fonseca, S.; Marques, J. J. G. S. M. Perdas de solo e água por erosão hídrica em sistemas florestais na região de Aracruz (ES). Revista Brasileira de Ciência do Solo, Viçosa, v.27, n.3, p.395403, 2003.

Meyer, L. D.; Zuhdi, B. A.; Coleman, N. L.; Prasad, S. N. Transport of sand-size sediment along crop row furrows. Transactions of the ASAE, St Joseph, v.26, n.1, p.106-111, 1983.
Mello, E. L.; Bertol, I.; Zaparolli, A. L. V. \& Carrafa, M. R. Perdas de solo e água em diferentes sistemas de manejo de um Nitossolo háplico submetido à chuva simulada. Revista Brasileira de Ciência do Solo, Viçosa, v.27, n.5, p.901-909, 2003.

Nacif, P. G. S. Ambientes naturais da Bacia Hidrográfica do Rio Cachoeira, com ênfase nos domínios pedológicos. Viçosa: UFV, 2000. 132p. Tese Doutorado

Paiva, E. M. C. de, Evolução de processo erosivo acelerado em trecho do Arroio Vacacai Mirim. Revista Brasileira de Recursos Hídricos, Porto Alegre, v.6, n.2, p.129-135, 2001.

Pereira, S. B.; Pruski, F. F.; Silva, da D. D.; Matos, A. T de. Despreendimento e arraste do solo pelo escoamento superficial. Revista Brasileira de Engenharia Agrícola e Ambiental, Campina Grande, v.7, n.3. p.423-429, 2003.

SAS Institute, Inc. The SAS System for windows: Releasa versão. 6.8, Cary, 1998. CD-Rom.

Schäffer, M. J.; Reicherdt, J. M.; Cassol, E. A.; Eltz, F. L. F.; Reinert, D. J. Erosão em sulcos em diferentes preparos e estados de consolidação do solo. Revista Brasileira de Ciência do Solo, Viçosa, v.25, p.419-430, 2001.

Silva, I. de F. Efeito de diferentes coberturas vegetais e de práticas conservacionistas no controle de erosão. Revista Brasileira de Ciência do Solo, Campinas, v.10, n.3, p.289-292, 1986.

Watson, D. A.; Laflen, J. M. Soil strength, slope and rainfall intensity effects on interril erosion. Transactions of the ASAE, St Joseph v.29, n.1, p.98-102, 1986. 